\title{
Longitudinal analysis of alcohol use and intimate partner violence perpetration among men with HIV in northern Vietnam
}

\author{
Rebecca B. Hershow ${ }^{\mathrm{a}, *}$, H. Luz McNaughton Reyes ${ }^{\mathrm{a}}$, Tran Viet Ha ${ }^{\mathrm{b}}$, Geetanjali Chander ${ }^{\mathrm{c}, \mathrm{d}}$, \\ Nguyen Vu Tuyet Mai ${ }^{\mathrm{b}, 1}$, Teerada Sripaipan ${ }^{\mathrm{a}}$, Constantine Frangakis ${ }^{\mathrm{c}, \mathrm{d}}$, David W. Dowdy ${ }^{\mathrm{c}, \mathrm{d}}$, \\ Carl Latkin ${ }^{\mathrm{c}, \mathrm{d}}$, Heidi E. Hutton ${ }^{\mathrm{d}}$, Audrey Pettifor ${ }^{\mathrm{a}}$, Suzanne Maman ${ }^{\mathrm{a}}$, Vivian F. Go ${ }^{\mathrm{a}}$ \\ ${ }^{a}$ University of North Carolina at Chapel Hill Gillings School of Global Public Health, 135 Dauer Drive, 302 Rosenau Hall, Chapel Hill, NC, 27599 , USA \\ ${ }^{\mathrm{b}}$ UNC Project Vietnam, Yen Hoa Health Clinic, Lot E2, Duong Dinh Nghe Street, Hanoi, Viet Nam \\ ' Johns Hopkins University Bloomberg School of Public Health, 615 N. Wolfe Street, Baltimore, MD, 21205, USA \\ ${ }^{\mathrm{d}}$ Johns Hopkins University School of Medicine, 600 N. Wolfe Street, Baltimore, MD, 21205, USA
}

\section{A R T I C L E IN F O}

Keywords:

Alcohol

Intimate partner violence

HIV/AIDS

Longitudinal analysis

Vietnam

Global health

\begin{abstract}
A B S T R A C T
Background: Alcohol use is a known risk factor for male-perpetrated intimate partner violence (IPV), although few studies have been conducted globally and among men with HIV (MWH). We estimated the longitudinal effects of alcohol use on IPV perpetration among MWH.

Methods: This study is a secondary analysis of randomized controlled trial data among male and female antiretroviral treatment patients with hazardous alcohol use in Thai Nguyen, Vietnam. Analyses were restricted to male participants who were married/cohabitating $(\mathrm{N}=313)$. Alcohol use was assessed as proportion days alcohol abstinent, heavy drinking, and alcohol use disorder (AUD) using the Timeline Followback and Mini International Neuropsychiatric Interview questionnaire. Multilevel modeling was used to estimate the effects of higher versus lower average alcohol use on IPV perpetration (between-person effects) and the effects of timespecific deviations in alcohol use on IPV perpetration (within-person effects).

Results: Participants with higher average proportion days alcohol abstinent had decreased odds of IPV perpetration (adjusted Odds Ratio $[\mathrm{aOR}]=0.43, \mathrm{p}=0.03$ ) and those with higher average heavy drinking and AUD had increased odds of IPV perpetration (Heavy drinking: aOR $=1.05, \mathrm{p}=0.002$; AUD: $\mathrm{aOR}=4.74$, $\mathrm{p}<0.0001$ ). Time-specific increases in proportion days alcohol abstinent were associated with decreased odds of IPV perpetration $(\mathrm{aOR}=0.39, \mathrm{p}=0.02)$ and time-specific increases in AUD were associated with increased odds of IPV perpetration ( $\mathrm{aOR}=2.95, \mathrm{p}=0.001$ ). Within-person effects for heavy drinking were non-significant.

Conclusions: Alcohol use is associated with IPV perpetration among Vietnamese men with HIV. In this context, AUD and frequent drinking are stronger correlates of IPV perpetration as compared to heavy drinking.
\end{abstract}

\section{Introduction}

Male-perpetrated intimate partner violence (IPV) is a pervasive and urgent public health problem. Globally, $30 \%$ of women have ever experienced IPV (World Health Organization [WHO], 2013), defined as psychological, physical, or sexual abuse perpetrated towards an intimate partner (WHO, 2010, 2013; Mitchell et al., 2016). Experiencing IPV leads to a range of health consequences, including HIV/STI infection, substance abuse, depression, physical injury, and death (WHO, 2013; Li et al., 2014).
There is substantial evidence that alcohol use is associated with male-perpetrated IPV (Fulu et al., 2013; Jansen et al., 2016), including three meta-analyses showing small to moderate effects of alcohol use on IPV perpetration (Ferrer et al., 2004; Foran and O'Leary, 2008; Stith et al., 2004). While nearly all studies included in these meta-analyses are cross-sectional, there are longitudinal studies demonstrating alcohol use leads to IPV perpetration (Crane et al., 2016; Temple et al., 2013; Yu et al., 2019). The relationship between alcohol use and IPV perpetration is often explained using two theoretical models. First, alcohol use may lead to IPV perpetration through immediate

\footnotetext{
* Corresponding author.

E-mail address: rhershow@live.unc.edu (R.B. Hershow).

${ }^{1}$ Present address: Vinmec Health Care System, 458 Minh Khai Street, Hai Ba Trung District, Hanoi, Viet Nam.
} 
psychopharmacological effects of alcohol, such as lowered inhibitions or distorted perceptions of cues, or through expectancy effects regarding the link between intoxication and aggression (Crane et al., 2016; Kachadourian et al., 2014; Reyes et al., 2012). Second, alcohol use may lead to increased relationship conflict, in turn leading to IPV perpetration (Fischer et al., 2005; Fischer and Wiersma, 2012; White and Chen, 2002). For example, alcohol use may lead to arguments with a partner about the amount of alcohol consumed and time together (Fischer and Wiersma, 2012; Foran and O'Leary, 2008).

Although the relationship between alcohol use and IPV perpetration has been well-established, most of this research has been conducted in Western countries (Crane et al., 2016; Ferrer et al., 2004; Foran and O'Leary, 2008). Few rigorous studies have examined the alcohol-IPV relationship in Vietnam, despite pervasive alcohol use and the high prevalence of IPV (Jansen et al., 2016; Lincoln, 2016; Luu et al., 2014). Over half $(58 \%)$ of women reported experiencing IPV by their husbands (General Statistics Office, 2010 ) an d $37 \%$ of me n reported having ever perpetrated IPV against their wife (Yount et al., 2015). Alcohol use and IPV perpetration are largely shaped by sociocultural norms and practices (WHO, 2010; Horton and Rydstrom, 2011), suggesting that the association between alcohol use and IPV perpetration may differ across cultural contexts. This is supported by the results from a multi-country study in Asia and the Pacific which found the strength of the alcohol-IPV relationship varied across countries and the relationship was non-significant in Muslim-majority societies (Fulu et al., 2013). To develop effective alcohol and IPV reduction interventions for implementation in Vietnam, it is critical to understand whether the associations between alcohol use and IPV perpetration among men in Vietnam are similar or different to other settings.

Further, there is a dearth of research on alcohol use and IPV perpetration among men with HIV globally. Although there is limited evidence, research suggests men with HIV may be at particularly high risk for IPV perpetration and forward HIV transmission (Hershow et al., 2020). Men with HIV have an elevated prevalence of hazardous alcohol use (Crane et al., 2017; Tran et al., 2013), a known correlate of IPV perpetration (Fulu et al., 2013; Gilchrist et al., 2017; Jansen et al., 2016) and other HIV transmission risk factors, such as poor antiretroviral treatment (ART) adherence, condomless sex, and unsupressed HIV viral load (Blashill et al., 2015; Glynn et al., 2019; McMahon et al., 2019). Research with sub-groups such as men with HIV should be a priority to improve men's health and wellbeing (Hatcher et al., 2019; Okafor et al., 2018) and to prevent forward HIV transmission (Chander et al., 2006; Hendershot et al., 2009; Tran et al., 2014).

In this study, we estimate the longitudinal effects of alcohol use on IPV perpetration among men with HIV and hazardous alcohol use in northern Vietnam. Hazardous alcohol use refers to a spectrum of alcohol use behavior, including exceeding weekly drinking limits and heavy episodic/binge drinking. As a meta-analytic review found that the effect size for the association between alcohol use and IPV perpetration varied by alcohol measure (Foran and O'Leary, 2008), three measures of alcohol use were used in analyses: proportion of days alcohol abstinent, number of heavy drinking days, and alcohol use disorder (AUD). Specific hypotheses include:

- At time points when men report higher levels of alcohol use than their own average, men will report increased IPV perpetration.

- Men who report higher as compared with lower mean levels of alcohol use will report increased IPV perpetration over time.

\section{Material and methods}

\subsection{Design}

This study is a secondary analysis of data from a three-arm randomized controlled trial (RCT) among clinic patients with HIV and hazardous alcohol use $(\mathrm{N}=440)$ in Thai Nguyen (Go et al., 2020). Thai
Nguyen is a semi-urban province in northern Vietnam located approximately $75 \mathrm{~km}$ north of Hanoi with a population of approximately 1 million. The RCT compared the effects of two evidence-based, manualguided, individually delivered interventions on alcohol use and viral load. There were three study arms: (1) Brief Intervention (two in-person sessions and two phone call sessions); (2) Combined Intervention (six in-person sessions and three optional group sessions); and (3) standard of care (Go et al., 2020; Hutton et al., 2018). Participants were randomly assigned to one of the three study arms in a 1:1:1 ratio.

\subsection{Participants}

Study participants were recruited from seven ART community clinics in Thai Nguyen. Once all ART clients were approached for recruitment in one clinic, recruitment efforts moved to the next clinic. The order of clinics that ART clients were recruited from was random. Inclusion criteria for eligibility included: (1) current client on ART at the clinic; (2) Alcohol Use Disorders Identification Test (AUDIT-C) score $\geq 4$ for men or $\geq 3$ for women (Babor et al., 2001); (3) 18 years of age or older; and (4) plan on residing in Thai Nguyen for the next 24 months. Exclusion criteria for eligibility included: (1) unable to participate due to psychological disturbance, cognitive impairment or threatening behavior towards study/clinic staff (assessed by study staff); (2) unwilling to provide locator information or informed consent; and (3) currently participating in other alcohol or drug use or HIV program or study. Of the 1559 individuals screened for eligibility, 1078 were not eligible, often due to screening negative for hazardous alcohol use based on the AUDIT-C ( $\mathrm{N}=1040 / 1078)$.

Eligible participants were asked to consent to enroll. Participants who provided written informed consent were assigned a unique identification number and completed the baseline questionnaire and Timeline Followback (TLFB) to measure daily alcohol use over the past 30 days (Sobell et al., 1996).

From March 2016 to June 2018, quantitative assessments were administered through face-to-face interviews in a private room at an ART clinic by trained interviewers at baseline, three, six, and 12 months. Participants also provided blood samples at every study visit to test for CD4 T-cell count, HIV viral load, and hepatitis B surface antigen rapid test. The duration of each visit was approximately two hours. The intervention was delivered to intervention participants between the study visits at baseline and three months. The assessment collected data on alcohol and drug use, involvement in community violence, exposure to violence as a child, and IPV. In the full sample, retention was $94 \%$ (405/430) at three months, $96 \%(410 / 427)$ at six months, and $94 \%$ $(390 / 414)$ at 12 months excluding those who were incarcerated $(\mathrm{n}=$ $11 / 440 ; 2.5 \%$ ) or died ( $n=15 / 440 ; 3.4 \%$ ) during the study period.

The study protocol received ethical approval from the Institutional Review Boards at the University of North Carolina Gillings School of Global Public Health, the Johns Hopkins University Bloomberg School of Public Health and the Thai Nguyen Center for Preventive Medicine.

\subsection{Measures}

\subsubsection{IPV perpetration}

Recent psychological, physical, and sexual IPV perpetration among any current or previous partner was measured with the widely used and validated six-item shortened Conflict Tactics Scale 2 (CTS2) (Murshid and Murshid, 2018; Nguyen, 2006; Straus and Douglas, 2004). Psychological, physical, and sexual IPV perpetration were each measured using two items. Response options varied based on the study visit. At baseline, participants were asked about any events of IPV in the past year. At the following study visits, the recall period was three months. Due to the differences in recall periods across study visits, the outcome will be referred to as "recent IPV perpetration." As the number of recent IPV events were skewed, the outcome variable was dichotomized to those who reported perpetrating psychological, physical, or sexual IPV 
at least once and those who did not (Benebo et al., 2018). Those who refused to or didn't know the answer were marked as missing.

\subsection{2 .Alcohol use}

Alcohol use was measured using TLFB, a tool that has been shown to be valid and reliable across multiple settings and populations (Fiellin et al., 2013; Vakili et al., 2008). The TLFB is an interviewer-administered assessment that reconstructs a daily behavior calendar to help prompt memory recall for alcohol consumption. Using the TLFB, alcohol use was assessed as proportion of days alcohol abstinent in past 30 days ( $0-1)$ and number of heavy drinking days in past 30 days. A heavy drinking day was defined as having more than four standard drinks per day for men (Alcohol Research: Current Reviews Editorial Staff, 2018). Prior to the study, a chemical analysis of commonly consumed alcoholic beverages in Thai Nguyen was conducted to define a "standard drink" that contained approximately $3 \%$ alcohol by volume (Hutton et al., 2018). For example, one can of beer and 2.3 shots of rice wine were each equivalent to one standard drink (Hutton et al., 2018). The number of standard drinks per day was calculated based on the type and number of alcoholic beverages that participants reported consuming.

To capture patterns of severity of hazardous alcohol use, AUD was measured using the Mini International Neuropsychiatric Interview questionnaire (MINI) Diagnostic and Statistical Manual of Mental Health Disorders, 4th edition (DSM IV) tool (Francis et al., 2015). The MINI consists of a set of items that measures alcohol dependence and a set of items that measures alcohol abuse, which are defined by level of drinking and mental or physical harm due to drinking (B abor et al., 2001). Based on the standard scoring method, participants who scored three or more on the alcohol dependence items and/or one or more on the alcohol abuse items were categorized as having an AUD (Francis et al., 2015).

\subsubsection{Covariates}

Covariates for the relationship between alcohol use and IPV perpetration were selected based on substantial theoretical or empirical evidence of potential confounding (Cunradi et al., 2014; Dasgupta et al., 2018; Gilchrist et al., 2017; Go et al., 2013; Jansen et al., 2016; Machisa et al., 2016; Tschann et al., 2005). Exposure to violence as a child comprised three items asking about ever witnessing interparental violence, experiencing physical abuse, or experiencing sexual abuse as a child. Responses were categorized as having been exposed to violence as a child if a participant answered yes to any of the three questions or no if a participant answered no to all three questions. Involvement in community violence ever was measured using two items that asked if they had ever been physically violent towards someone in their community or had ever experienced physical violence by someone in their community (Dahlberg et al., 1998). As experiencing and perpetrating community violence are known risk factors for IPV perpetration (Beyer et al., 2015; Gilchrist et al., 2017; Jansen et al., 2016; Reed et al., 2009), we created a composite variable for involvement in community violence ever.

The remaining covariates, including education (primary school or less/secondary school or less/high school or less/technical training or college or university or less), age, employment status (employed full- or part-time/unemployed or retired), and injection drug use in the past three months, were collected via self-report. As both alcohol reduction interventions significantly reduced alcohol use at each follow-up study visit as compared to the standard of care group (Go et al., 2020), intervention arm was also included as a covariate to control for intervention effects on alcohol use and IPV perpetration. Intervention arm was documented during the computer-generated randomization process.

\subsection{Analyses}

We restricted our analysis to male participants who reported being married or cohabitating with a partner at baseline $(\mathrm{N}=313)$. Previous research among men with HIV in Vietnam has shown that the alcoholIPV relationship operates differently for men who were married or cohabitating versus those who were not (Hershow et al., 2020).

The longitudinal effects of alcohol use on IPV perpetration were estimated with multilevel growth models using maximum likelihood based on the Laplace estimation (Breslow and Clayton, 1993). The models were specified at two levels in which the repeated measure of the outcome (level one) was nested within individuals (level two). This approach allowed for the separation of the total variance in IPV perpetration into variation in an individual's IPV perpetration over time and variation across individuals in IPV perpetration. As a result, we were able to examine both the time-varying (within-person) and proximal (between-person) effects of alcohol use on IPV perpetration.

Linear and quadratic functional forms were tested to determine the best-fitting unconditional growth model for IPV perpetration. If the variance component for the random effect could not be estimated, it was removed from the model; if the fixed effect was then found to be non-significant, it was also removed from the model.

Centering strategies were used with all variables included in the analysis (Enders and Tofighi, 2007). The variable for wave of data collection was re-coded to start at zero so that the intercept represents the log odds of IPV perpetration at baseline. Alcohol use variables estimating time-varying effects were person-mean centered and alcohol use variables estimating proximal effects were grand-mean centered after calculating the person means. Other categorical covariates were dummy coded and age (years) was grand-mean centered.

Analysis was conducted using SAS 9.4 (SAS Institute Inc., Cary, NC). The same analytic approach was used for each of the three alcohol use variables. After determining the best-fitting unconditional growth model, the centered alcohol use variables and covariates were added to the model. The adjusted conditional growth model tested the timevarying and proximal effects of alcohol use on IPV perpetration adjusting for covariates (see Fig. 1).

\section{Results}

\subsection{Descriptive statistics}

The sample comprised 313 male participants who were married or cohabitating (see Table 1). The mean age of participants was 40.8 years $(\mathrm{SD}=5.6)$ at baseline. Most participants had a high school education or less $(\mathrm{N}=189 ; 60.4 \%)$. At baseline, $14.4 \%(\mathrm{~N}=45)$ of participants had not achieved viral suppression (less than 20 copies $/ \mathrm{mL}$ ).

Median percent days alcohol abstinent in the past 30 days increased over the study from $36.7 \%(\mathrm{SD}=33.1$ ) at baseline to $76.7 \%$ (SD = 36.9 ) at 12-month follow-up. Median number of heavy drinking days in the past 30 days decreased over the study from 2.0 days $(S D=10.1)$ at baseline to 1.0 day ( $S D=8.7$ ) at 12 -month follow-up. The proportion of participants screening positive for AUD decreased from $39.6 \%(\mathrm{~N}=$ $124)$ at baseline to $19.4 \%(\mathrm{~N}=54)$ at 12-month follow-up.

At baseline, 94 participants (30.0\%) reported any form of IPV perpetration in the last 12 months; psychological IPV was the most prevalent ( $\mathrm{N}=82 ; 26.2 \%$; see Table 2). At three-month follow-up, the prevalence of any form of recent IPV perpetration decreased to $15.4 \%(\mathrm{~N}=44)$, as expected due to the shorter reference period. The prevalence estimates remained around this level throughout the rest of the study (six-month follow-up: $\mathrm{N}=47,16.1 \%$; 12-month follow-up: $\mathrm{N}=42,15.1 \%$ ).

\subsection{Trajectories of IPV perpetration: unconditional growth model}

The best fitting unconditional model for IPV perpetration included a random intercept with random and linear fixed effects for time (see 


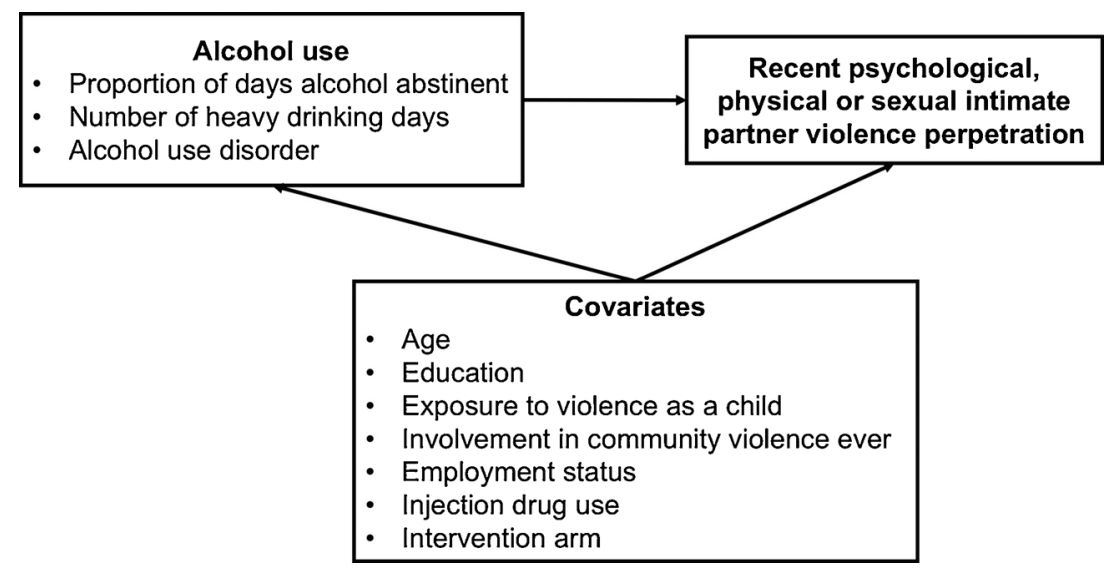

Fig. 1. Analytic model.

Table 1

Characteristics of male participants who were married or cohabitating with a partner $(\mathrm{N}=313)^{\mathrm{a}}$.

\begin{tabular}{|c|c|c|c|c|}
\hline & $\begin{array}{l}\text { Baseline }(\mathrm{N} \\
=313) \\
\mathrm{N}(\%)\end{array}$ & $\begin{array}{l}3 \text { months } \\
(\mathrm{N}=287)\end{array}$ & $\begin{array}{l}6 \text { months } \\
(\mathrm{N}=292)\end{array}$ & $\begin{array}{l}12 \text { months } \\
(\mathrm{N}=279)\end{array}$ \\
\hline \multicolumn{5}{|l|}{ Sociodemographics } \\
\hline Mean age in years (SD) & $40.8(5.6)$ & & & \\
\hline \multicolumn{5}{|l|}{ Highest level of education } \\
\hline $\begin{array}{l}\text { Technical training/ } \\
\text { College or university } \\
\text { or less }\end{array}$ & $52(16.6)$ & & & \\
\hline High school or less & $189(60.4)$ & & & \\
\hline $\begin{array}{l}\text { Secondary school or } \\
\text { less }\end{array}$ & $48(15.3)$ & & & \\
\hline Primary school or less & $24(7.7)$ & & & \\
\hline \multicolumn{5}{|l|}{ Employment status } \\
\hline $\begin{array}{l}\text { Employed full- or part- } \\
\text { time }\end{array}$ & $262(83.7)$ & $243(84.7)$ & $255(87.3)$ & $245(87.8)$ \\
\hline Unemployed/Retired & $51(16.3)$ & $44(15.3)$ & $37(12.7)$ & $34(12.2)$ \\
\hline \multicolumn{5}{|l|}{ Viral suppression ${ }^{\mathrm{b}, \mathrm{c}}$} \\
\hline No & $45(14.4)$ & 39 (13.6) & 35 (12.0) & $42(15.1)$ \\
\hline Yes & $268(85.6)$ & $247(86.4)$ & $257(88.0)$ & 237 (84.9) \\
\hline \multicolumn{5}{|l|}{ Alcohol Use } \\
\hline $\begin{array}{l}\text { Median percent days } \\
\text { abstinent in past } 30 \\
\text { days (SD) }\end{array}$ & $36.7(33.1)$ & $70.0(35.6)$ & $76.7(37.3)$ & 76.7 (36.9) \\
\hline $\begin{array}{l}\text { Median number of heavy } \\
\text { drinking days in past } \\
30 \text { days (SD) }\end{array}$ & $2.0(10.1)$ & $1.0(8.7)$ & $0.0(8.6)$ & $1.0(8.7)$ \\
\hline \multicolumn{5}{|l|}{ Alcohol use disorder (AUD) } \\
\hline No & $189(60.4)$ & $210(73.2)$ & $223(76.4)$ & $225(80.6)$ \\
\hline Yes & $124(39.6)$ & $77(26.8)$ & $69(23.6)$ & $54(19.4)$ \\
\hline \multicolumn{5}{|l|}{ Psychosocial Factors } \\
\hline \multicolumn{5}{|l|}{$\begin{array}{l}\text { Injection drug use in past } \\
3 \text { months }\end{array}$} \\
\hline No & $244(78.0)$ & $226(79.0)$ & $228(78.1)$ & $222(79.6)$ \\
\hline Yes & $69(22.0)$ & $60(21.0)$ & $64(21.9)$ & $57(20.4)$ \\
\hline \multicolumn{5}{|c|}{ Exposed to violence as a child ${ }^{\mathrm{d}}$} \\
\hline No & $199(63.6)$ & & & \\
\hline Yes & $114(36.4)$ & & & \\
\hline \multicolumn{5}{|c|}{ Ever involved in community violence ${ }^{c}$} \\
\hline No & $178(56.9)$ & $176(61.5)$ & $173(59.2)$ & $140(50.2)$ \\
\hline Yes & $135(43.1)$ & $110(38.5)$ & $119(40.8)$ & $139(49.8)$ \\
\hline
\end{tabular}

Note: $\mathrm{SD}=$ Standard deviation.

a Percentages may not sum to 100 due to rounding.

b Achieving viral suppression was defined as having less than 20 copies/mL.

c Missing data due to refused to answer or don't know: Viral suppression at 3 months: $\mathrm{N}=1$; Injection drug use at 3 months: $\mathrm{N}=1$; Ever involved in community violence at 3 months: $\mathrm{N}=1$.

d Exposed to violence as a child includes having ever witnessed interparental violence as a child or experienced physical or sexual abuse as a child.
Table 2

Prevalence of intimate partner violence perpetration across study visits ${ }^{\mathrm{a}}$.

\begin{tabular}{|c|c|c|c|c|}
\hline & $\begin{array}{l}\text { Baseline } \\
(\mathrm{N}=313) \\
\mathrm{N}(\%)\end{array}$ & $\begin{array}{l}3 \text { months } \\
(\mathrm{N}=287)\end{array}$ & $\begin{array}{l}6 \text { months } \\
(\mathrm{N}=292)\end{array}$ & $\begin{array}{l}12 \text { months } \\
(\mathrm{N}=279)\end{array}$ \\
\hline \multicolumn{5}{|c|}{ Recent Psychological IPV Perpetration ${ }^{\mathrm{b}}$} \\
\hline No & $231(73.8)$ & $250(87.4)$ & $252(86.3)$ & $242(86.7)$ \\
\hline Yes & $82(26.2)$ & $36(12.6)$ & $40(13.7)$ & $37(13.3)$ \\
\hline \multicolumn{5}{|c|}{ Recent Physical IPV Perpetration } \\
\hline No & $298(95.2)$ & $282(98.3)$ & $285(97.6)$ & $275(98.6)$ \\
\hline Yes & $15(4.8)$ & $5(1.7)$ & $7(2.4)$ & $4(1.4)$ \\
\hline \multicolumn{5}{|c|}{ Recent Sexual IPV Perpetration } \\
\hline No & $293(93.6)$ & $276(96.2)$ & $285(97.6)$ & $270(96.8)$ \\
\hline Yes & $20(6.4)$ & $11(3.8)$ & $7(2.4)$ & $9(3.2)$ \\
\hline \multicolumn{5}{|c|}{ Recent Physical/Sexual IPV Perpetration } \\
\hline No & $280(89.5)$ & $272(94.8)$ & 279 (95.5) & $266(95.3)$ \\
\hline Yes & $33(10.5)$ & $15(5.2)$ & $13(4.5)$ & $13(4.7)$ \\
\hline \multicolumn{5}{|c|}{ Any Form of Recent IPV Perpetration ${ }^{\mathrm{b}}$} \\
\hline No & $219(70.0)$ & $242(84.6)$ & 245 (83.9) & 237 (84.9) \\
\hline Yes & $94(30.0)$ & $44(15.4)$ & $47(16.1)$ & $42(15.1)$ \\
\hline
\end{tabular}

Note: $\mathrm{IPV}=$ Intimate partner violence.

${ }^{\text {a }}$ Percentages may not sum to 100 due to rounding.

b Missing data due to refused to answer or don't know: Recent psychological IPV perpetration at 3 months: $\mathrm{N}=1$; Any form of recent IPV perpetration at 3 months: $\mathrm{N}=1$.

Table 3

Unconditional growth model: Trajectories of intimate partner violence perpetration over time $(\mathrm{N}=313)$.

\begin{tabular}{lll}
\hline & Coefficient (SE) or OR $(95 \% \mathrm{CI}), \mathrm{p}$-value \\
\hline $\begin{array}{l}\text { Fixed Effects } \\
\text { Intercept }\end{array}$ & $-1.09(0.14)$ & $<0.0001$ \\
Time & $0.45(0.34,0.59)$ & $<0.0001$ \\
Random Effects & & \\
$\quad$ Variance Components & & \\
$\quad$ Covariance & $0.53(0.54)$ & \\
$\quad$ Variance & $0.12(0.24)$ & \\
Model Fit & & \\
$\quad$ AIC & 1090.05 & \\
$\quad$ BIC & 1105.04 & \\
Neg 2 LL & 1082.05 &
\end{tabular}

Note: $\mathrm{SE}=$ Standard error; $\mathrm{OR}=$ Odds ratio; $\mathrm{CI}=$ Confidence Interval; $\mathrm{AIC}=$ Akaike information criterion; BIC = Bayesian information criterion; Neg $2 \mathrm{LL}$ $=$ Negative 2 log likelihood.

Table 3). The linear parameter for time showed that the odds of IPV perpetration significantly decreased over time $(\mathrm{OR}=0.45,95 \% \mathrm{CI}$ $0.34,0.59, \mathrm{p}<0.0001$ ). There was also significant variance in IPV perpetration between participants at baseline (Intercept: $\mathrm{b}=-1.09$, SE $=0.14, \mathrm{p}<0.0001)$. 
Table 4

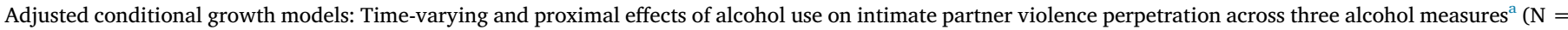
313).

\begin{tabular}{|c|c|c|c|c|c|c|}
\hline \multirow{3}{*}{ Fixed Effects } & \multicolumn{2}{|c|}{ Proportion days alcohol abstinent } & \multicolumn{2}{|l|}{ Heavy drinking } & \multicolumn{2}{|c|}{ Alcohol use disorder (AUD) ${ }^{\mathrm{b}}$} \\
\hline & \multicolumn{6}{|c|}{ Coefficient (SE) or aOR (95\% CI), p-value } \\
\hline & & & & & & \\
\hline Intercept & $-0.73(0.41)$ & 0.08 & $-0.55(0.41)$ & 0.09 & $-0.94(0.42)$ & 0.03 \\
\hline Time & $0.53(0.41,0.70)$ & $<0.0001$ & $0.50(0.38,0.65)$ & $<0.0001$ & $0.53(0.40,0.70)$ & $<0.0001$ \\
\hline \multicolumn{7}{|l|}{ Alcohol use } \\
\hline Time-varying & $0.39(0.17,0.88)$ & 0.02 & $0.99(0.96,1.02)$ & 0.61 & $2.95(1.59,5.46)$ & 0.001 \\
\hline Proximal & $0.43(0.20,0.91)$ & 0.03 & $1.05(1.02,1.08)$ & 0.002 & $4.74(2.31,9.71)$ & $<0.0001$ \\
\hline \multicolumn{7}{|l|}{ Random Effects } \\
\hline \multicolumn{7}{|c|}{ Variance Components } \\
\hline Covariance & $-0.007(0.25)$ & & $-0.10(0.26)$ & & $-0.10(0.19)$ & \\
\hline Variance & $0.56(0.55)$ & & $0.71(0.58)$ & & $0.74(0.47)$ & \\
\hline \multicolumn{7}{|l|}{ Model Fit } \\
\hline AIC & 1052.89 & & 1052.37 & & 1025.82 & \\
\hline BIC & 1112.82 & & 1112.31 & & 1085.76 & \\
\hline Neg 2 LL & 1020.89 & & 1020.37 & & 993.82 & \\
\hline
\end{tabular}

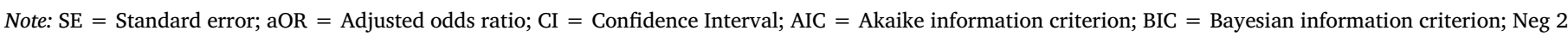
$\mathrm{LL}=$ Negative 2 log likelihood.

a Controlling for education, grand-mean centered age, exposure to violence as a child, employment status, injection drug use, involvement in community violence ever, and intervention arm.

b A random slope for time-varying AUD was added to this model as model fit improved when it was included.

\subsection{Adjusted analyses}

\subsubsection{Proportion days alcohol abstinent}

As expected, the time-varying and proximal effects of proportion days alcohol abstinent on IPV perpetration were negative (see Table 4). The time-varying effect demonstrates that at time points when participants reported higher proportion days alcohol abstinent than average, they were 0.39 times as likely to report IPV perpetration (95\% CI 0.17 , $0.88, \mathrm{p}=0.02$ ). The proximal effect shows that participants who reported higher as compared to lower average proportion days alcohol abstinent over the study period were 0.43 times as likely to report IPV perpetration over time ( $95 \% \mathrm{CI} 0.20,0.91, \mathrm{p}=0.03$ ). As higher proportion days alcohol abstinent indicate less alcohol use, these inverse relationships between proportion days alcohol abstinent and IPV perpetration were expected.

\subsubsection{Heavy drinking}

Contrary to expectations, the time-varying effect of heavy drinking on IPV perpetration was inconclusive (aOR $=0.99,95 \%$ CI 0.96, 1.02, $\mathrm{p}=0.61$; see Table 4). However, as expected, the proximal effect showed that reporting higher as compared to lower average levels of heavy drinking over the study period was associated with higher odds of IPV perpetration over time $(\mathrm{aOR}=1.05,95 \% \mathrm{CI} 1.02,1.08, \mathrm{p}=$ 0.002).

\subsubsection{Alcohol use disorder (AUD)}

As hypothesized, the time-varying and proximal effects of AUD were associated with higher odds of IPV perpetration (see Table 4). Participants who screened positive for AUD across the study as compared to negative were 4.74 times as likely to report IPV perpetration (95\% CI $2.31,9.71, \mathrm{p}<0.0001$ ). Controlling for the effect of average tendency to report AUD, participants were 2.95 times as likely to report IPV perpetration at times when they screened positive for AUD (95 \% CI $1.59,5.46, \mathrm{p}=0.001$ ).

\section{Discussion}

To our knowledge, this is the first study to examine the longitudinal relationship between alcohol use and IPV perpetration among men with HIV. Findings demonstrate that hazardous drinking is associated with IPV perpetration in this population. IPV and HIV prevention interventions targeting this group should incorporate alcohol reduction services into HIV care and treatment. Clinic-based psychosocial counseling interventions targeting men with hazardous alcohol use in the United States and Zambia effectively reduced IPV perpetration (Murray et al., 2020; O'Farrell et al., 2003; Stuart et al., 2003), offering a promising IPV prevention strategy to test in low-resource settings.

Differing types of longitudinal effects were found across alcohol measures, suggesting that the nature of the alcohol-IPV relationship varies by drinking pattern, as shown in other alcohol and violence research (Foran and O'Leary, 2008). For proportion days alcohol abstinent and AUD, increases in alcohol use at one time point increased the odds of IPV perpetration at the same time point. These observed effects may be explained by the proximal effects model, which is used to explain the acute effects of alcohol use on IPV perpetration (Crane et al., 2016; Kachadourian et al., 2014; Reyes et al., 2012). According to this model, the immediate intoxication effects of alcohol increases an individual's focus on insult or anger and reduces focus on affection or empathy, leading to an inability to use nonaggressive conflict resolution strategies with a partner (Clements and Schumacher, 2010; Crane et al., 2016). This model also suggests that individuals' expectancies about the link between alcohol and violence are activated when they are intoxicated, leading to aggression (Kachadourian et al., 2014; Quigley and Leonard, 2006). Additionally, lower average proportion days alcohol abstinent, and higher average heavy drinking and AUD across the study increased the odds of IPV perpetration. These observed effects may be explained by the indirect effects model, which posits that elevated alcohol use leads to poor relationship quality, which in turn leads to IPV perpetration over time (Fischer et al., 2005; White and Chen, 2002). To inform development of IPV prevention interventions for this population, future research should assess whether anger and relationship quality explain the longitudinal effects of alcohol use on IPV perpetration.

The relationship between alcohol use and IPV perpetration may also be explained by unmeasured confounding. The spurious effects model posits that individuals with deviant characteristics, such as antisocial personality traits and hostility, may be prone to engaging in hazardous drinking and IPV perpetration, explaining the alcohol-IPV relationship (Osgood et al., 1988). However, studies have found that the association between alcohol use and IPV perpetration remains after controlling for these potential confounders (Leonard and Senchak, 1993; Pan et al., 1994). For men with HIV, this spurious model may need to be adapted 
to consider unique characteristics in this population that may drive hazardous drinking and IPV perpetration, such as HIV-specific coping strategies, anger, or psychological distress (McIntosh et al., 2015; Zhao et al., 2019).

Our hypotheses on the relationship between heavy drinking and IPV perpetration were not fully supported by results. The magnitude of the proximal effect $\mathrm{w}$ as s mall a nd the $\mathrm{t}$ ime-varying e ffect wa s non-significant. When compared to results for the other measures of alcohol use, findings suggest that heavy drinking may not be the strongest risk factor for IPV perpetration in this population. There are a couple probable explanations for these results. First, as alcohol use is considered a conduit for men's violent behavior, women may avoid or placate their husbands when they are heavily intoxicated, reducing the opportunity for IPV (Hershow et al., 2017; Rydstrom, 2003). Qualitative research in other settings has suggested women utilize such strategies to avoid experiencing alcohol-related IPV (Wilson et al., 2017). Second, men may not remember or accurately remember perpetrating IPV after drinking heavily, as they may recall the positive social consequences of heavy drinking over the negative (Graham, 2003; Wilson et al., 2017). This is particularly possible among a socially isolated group such as men with HIV, as heavy drinking often occurs at social events, which act as key access points for social support (Hershow et al., 2018; Lincoln, 2016). While reducing heavy drinking is often a primary aim for alcohol and IPV reduction interventions (Fals-Stewart et al., 2002; Stuart et al., 2013), our findings suggest that reducing AUD and frequent drinking is also important for interventions targeting men with HIV in Vietnam.

As variables were measured using self-report and the questionnaire was interviewer-administered, responses may have been subject to social desirability and recall bias. Social desirability may have varied by study arm. Intervention participants may have considered the questionnaires as part of the intervention and been more honest than those in the standard of care group. On the contrary, intervention participants may have been more likely to provide socially desirable responses due to exposure to the intervention content. If present, the social desirability bias would have likely led to under-reporting of IPV perpetration (Perinelli and Gremigni, 2016; Sugarman and Hotaling, 1997). However, interviewers underwent extensive training on questionnaire administration, minimizing the likelihood of social desirability bias. Additionally, recall and social desirability bias may have influenced alcohol use estimates, although sub-analyses of the study data conducted by Go et al. (Go et al., 2020) validated the self-report alcohol measures using phosphatidylethanol (PEth), a direct metabolite of alcohol use that acts as a biomarker (Hahn et al., 2012).

We are unable to conclude that all participants were in heterosexual relationships due to missing data $(\mathrm{N}=42 / 313)$. However, the available data show that all participants only reported having female sexual partners recently and female main partners.

Alcohol use and IPV perpetration have different response frames in the questionnaire. The response frame for alcohol use measures is the last 30 days and the response frames for IPV perpetration varies from the last 12 months to the last three months, depending on the data collection time point (baseline: IPV perpetration in last 12 months; follow-up visits: IPV perpetration in last three months). This mismatch in response frames is a limitation when examining the time-varying effects of a lcohol use on IPV perpetration. However, the alcohol use variables are intended to measure alcohol use since the last data collection time point. When using the TLFB, research has shown that a recall period of 30 days can be used to estimate annual consumption (Vakili et al., 2008). Daily diary studies offer an optimal approach for establishing temporality when estimating time-varying effects of alcohol use on IPV perpetration (Sheehan and Lau-Barraco, 2019; Shorey et al., 2014). Nonetheless, the link between alcohol use and IPV perpetration is commonly explained by the immediate psychopharmacological effects of a lcohol u se o $\mathrm{n}$ a ggression (Crane e t a 1., 2016; Kachadourian et al., 2014; Reyes et al., 2012), suggesting that it is appropriate to examine the alcohol-IPV relationship at the same time point. Additionally, the three-month recall period for the IPV outcome at endline does not fully span the lag between the six- and 12-month study visits, suggesting the magnitude of the proximal effects of alcohol use on IPV perpetration may be underestimated. Further, it is plausible that alcohol use and IPV perpetration have a bidirectional relationship as men may also use alcohol to cope after perpetrating IPV (Kulis et al., 2019). Supplemental analyses suggest baseline alcohol use predicts IPV perpetration (Supplemental Table 1), although future research should explore the possibility of bidirectionality.

\section{Conclusions}

This longitudinal study contributes important findings on alcohol use and IPV perpetration in a high-risk, understudied population. Results suggest that the strength and nature of the relationship between alcohol use and IPV perpetration may vary across drinking patterns, underscoring the importance of measuring alcohol use in multiple ways and estimating multiple types of longitudinal effects. For all measures of alcohol use, reporting greater levels of alcohol use on average was associated with higher odds of IPV perpetration over time. Further, time-specific increases in alcohol use were associated with higher odds of IPV perpetration for measures of proportion days alcohol abstinent and AUD. To prevent IPV perpetration and forward HIV transmission among men with HIV, psychosocial counseling interventions should address alcohol use with a focus on reducing frequent drinking and AUD.

\section{Role of funding source}

This study was funded by the National Institute on Drug Abuse (NIDA) of the National Institutes of Health [grant number R01 DA037440]. This work was also supported by the University of North Carolina at Chapel Hill Center for AIDS Research (CFAR) [grant number P30 AI050410] and the National Institute of Allergy and Infectious Diseases (NIAID) [grant number T32 AI007001].

\section{Contributors}

All authors participated in the research and article preparation and approved of the final manuscript before submission to the journal. VFG, TVH, GC, DWD, CL, and HEH oversaw the clinical trial and contributed to writing and reviewing the manuscript; NVTM and TS oversaw data management and reviewed the manuscript; RBH conducted the analyses and drafted the manuscript; HLMR and CF supported the analyses and contributed to writing and reviewing the manuscript; AP and SM contributed to writing and reviewing the manuscript.

\section{Declaration of Competing Interest}

None.

\section{Acknowledgements}

This study was funded by the National Institute on Drug Abuse of the National Institutes of Health under grant R01 DA037440. This work was also supported by the University of North Carolina at Chapel Hill Center for AIDS Research (CFAR) under grant P30 AI050410 and the National Institute of Allergy and Infectious Diseases under grant T32 AI007001. The content is solely the responsibility of the authors and does not necessarily represent the official views of the National Institutes of Health. We would also like to thank the Thai Nguyen Center for Preventive Medicine for their support. 
Appendix A. Supplementary data

Supplementary material related to this article can be found, in the online version, at https://doi.org/10.1016/j.drugalcdep.2020.108098.

\section{References}

Alcohol Research: Current Reviews Editorial Staff, 2018. Drinking patterns and their definitions. Alcohol Res. 39 (1), 17-18.

Babor, T.F., Higgins-Biddle, J.C., Saunders, J.B., Monteiro, M.G., 2001. The Alcohol Use Disorders Identification Test Guidelines for Use in Primary Care.

Benebo, F.O., Schumann, B., Vaezghasemi, M., 2018. Intimate partner violence against women in Nigeria: a multilevel study investigating the effect of women's status and community norms. BMC Womens Health 18 (1), 136.

Beyer, K., Wallis, A.B., Hamberger, L.K., 2015. Neighborhood environment and intimate partner violence: a systematic review. Trauma Violence Abuse 16 (1), 16-47.

Blashill, A.J., Bedoya, C.A., Mayer, K.H., O'Cleirigh, C., Pinkston, M.M., Remmert, J.E Mimiaga, M.J., Safren, S.A., 2015. Psychosocial syndemics are additively associated with worse ART adherence in HIV-infected individuals. AIDS Behav. 19 (6), 981-986.

Breslow, N.E., Clayton, D.G., 1993. Approximate inference in generalized linear mixed models. J. Am. Stat. Assoc. 88 (421), 9-25.

Chander, G., Lau, B., Moore, R.D., 2006. Hazardous alcohol use: a risk factor for nonadherence and lack of suppression in HIV infection. J. Acquir. Immune Defic. Syndr. 43 (4), 411-417.

Clements, K., Schumacher, J.A., 2010. Perceptual biases in social cognition as potential moderators of the relationship between alcohol and intimate partner violence. Aggress. Violent Behav. 15 (5), 357-368.

Crane, C.A., Godleski, S.A., Przybyla, S.M., Schlauch, R.C., Testa, M., 2016. The proximal effects of acute alcohol consumption on male-to-female aggression: a meta-analytic review of the experimental literature. Trauma Violence Abuse 17 (5), 520-531.

Crane, H.M., McCaul, M.E., Chander, G., Hutton, H., Nance, R.M., Delaney, J.A.C. Merrill, J.O., Lau, B., Mayer, K.H., Mugavero, M.J., Mimiaga, M., Willig, J.H., Burkholder, G.A., Drozd, D.R., Fredericksen, R.J., Cropsey, K., Moore, R.D., Simoni, J.M., Christopher Mathews, W., Eron, J.J., Napravnik, S., Christopoulos, K., Geng, E., Saag, M.S., Kitahata, M.M., 2017. Prevalence and factors associated with hazardous alcohol use among persons living with HIV across the US in the current era of antiretroviral treatment. AIDS Behav. 21 (7), 1914-1925.

Cunradi, C.B., Mair, C., Todd, M., 2014. Alcohol outlet density, drinking contexts and intimate partner violence: a review of environmental risk factors. J. Drug Educ. 44 (1-2), 19-33.

Dahlberg, L.L., Toal, S.B., Behrens, C.B., 1998. Measuring violence-related attitudes, beliefs, and behaviors among youths: a compendium of assessment tools. Division of Violence Prevention, National Center for Injury Prevention and Control. Centers for Disease Control and Prevention, Atlanta, GA.

Dasgupta, A., Silverman, J., Saggurti, N., Ghule, M., Donta, B., Battala, M., Nair, S., Gajanan, V., Raj, A., 2018. Understanding men's elevated alcohol use, gender equity ideologies, and intimate partner violence among married couples in rural India. Am. J. Mens Health 12 (4), 1084-1093.

Enders, C.K., Tofighi, D., 2007. Centering predictor variables in cross-sectional multilevel models: a new look at an old issue. Psychol. Methods 12 (2), 121-138.

Fals-Stewart, W., Kashdan, T.B., O'Farrell, T.J., Birchler, G.R., 2002. Behavioral couples therapy for drug-abusing patients: effects on partner violence. J. Subst. Abuse Treat. 22 (2), 87-96.

Ferrer, V.B., Garcia, E., Manassero, M.A., Gili, M., 2004. Meta-analytic study of differential characteristics between batterers and non-batterers: the case of psychopathology and consumption of alcohol and drugs. Psykhe 13 (1), 141-156.

Fiellin, D.A., McGinnis, K.A., Maisto, S.A., Justice, A.C., Bryant, K., 2013. Measuring alcohol consumption using Timeline Followback in non-treatment-seeking medical clinic patients with and without HIV infection: 7-, 14-, or 30-day recall. J. Stud. Alcohol Drugs 74 (3), 500-504.

Fischer, J.L., Wiersma, J.D., 2012. Romantic relationships and alcohol use. Curr. Drug Abuse Rev. 5 (2), 98-116.

Fischer, J.L., Fitzpatrick, J., Cleveland, B., Lee, J.M., McKnight, A., Miller, B., 2005. Binge drinking in the context of romantic relationships. Addict. Behav. 30 (8), 1496-1516.

Foran, H.M., O'Leary, K.D., 2008. Alcohol and intimate partner violence: a meta-analytic review. Clin. Psychol. Rev. 28 (7), 1222-1234.

Francis, J.M., Helander, A., Kapiga, S.H., Weiss, H.A., Grosskurth, H., 2015. Validation of the MINI (DSM IV) tool for the assessment of alcohol dependence among young people in Northern Tanzania using the alcohol biomarker phosphatidylethanol (PEth). Int. J. Environ. Res. Public Health 12 (11), 14021-14033.

Fulu, E., Jewkes, R., Roselli, T., Garcia-Moreno, C., Team, U.N.M.-C.C.-s.S.o.M.V.R, 2013. Prevalence of and factors associated with male perpetration of intimate partner violence: findings from the UN multi-country cross-sectional study on men and violence in Asia and the Pacific. Lancet Glob. Health 1 (4), e187-207.

General Statistics Office, 2010. "Keeping Silent Is Dying": Results from the National Study on Domestic Violence Against Women in Vietnam. General Statistics Office of Vietnam, Hanoi, Vietnam.

Gilchrist, G., Radcliffe, P., Noto, A.R., d'Oliveira, A.F., 2017. The prevalence and factors associated with ever perpetrating intimate partner violence by men receiving substance use treatment in Brazil and England: a cross-cultural comparison. Drug Alcohol Rev. 36 (1), 34-51.

Glynn, T.R., Safren, S.A., Carrico, A.W., Mendez, N.A., Duthely, L.M., Dale, S.K., Jones, D.L., Feaster, D.J., Rodriguez, A.E., 2019. High levels of syndemics and their association with adherence, viral non-suppression, and biobehavioral transmission risk in
Miami, a U.S. city with an HIV/AIDS epidemic. AIDS Behav. 23 (11), 2956-2965.

Go, V.F., Minh, N.L., Frangakis, C., Ha, T.V., Latkin, C.A., Sripaipan, T., Davis, W., Zelaya, C., Ngoc, N.P., Quan, V.M., 2013. Decreased injecting is associated with increased alcohol consumption among injecting drug users in northern Vietnam. Int. J. Drug Policy 24 (4), 304-311.

Go, V.F., Hutton, H.E., Ha, T.V., Chander, G., Latkin, C.A., Mai, N.V.T., Quynh, B.X., Vu, N.Q., Vu, P.T., Sripaipan, T., Lancaster, K.E., Blackburn, N., Hershow, R.B., Dowdy, D.W., Frangakis, C., 2020. Two integrated interventions to reduce alcohol use and increase viral suppression among ART clients in Vietnam: a randomized controlled comparative effectiveness trial. Manuscript submitted for publication. JAMA Network Open.

Graham, K., 2003. The yin and yang of alcohol intoxication: implications for research on the social consequences of drinking. Addiction 98 (8), 1021-1023.

Hahn, J.A., Dobkin, L.M., Mayanja, B., Emenyonu, N.I., Kigozi, I.M., Shiboski, S., Bangsberg, D.R., Gnann, H., Weinmann, W., Wurst, F.M., 2012. Phosphatidylethanol (PEth) as a biomarker of alcohol consumption in HIV-positive patients in sub-Saharan Africa. Alcohol. Clin. Exp. Res. 36 (5), 854-862.

Hatcher, A.M., Gibbs, A., McBride, R.S., Rebombo, D., Khumalo, M., Christofides, N.J., 2019. Gendered syndemic of intimate partner violence, alcohol misuse, and HIV risk among peri-urban, heterosexual men in South Africa. Soc. Sci. Med., 112637.

Hendershot, C.S., Stoner, S.A., Pantalone, D.W., Simoni, J.M., 2009. Alcohol use and antiretroviral adherence: review and meta-analysis. J. Acquir. Immune Defic. Syndr. 52 (2), 180-202.

Hershow, R.B., Bhadra, M., Mai, N.V.T., Sripaipan, T., Ha, T.V., Go, V.F., 2017. A qualitative study with women living with HIV on perceived gender norms and experiences of intimate partner violence in Northern Vietnam. J. Interpers. Violence, 886260517724834.

Hershow, R.B., Zuskov, D.S., Vu Tuyet Mai, N., Chander, G., Hutton, H.E., Latkin, C., Vuong, N.D., Sripaipan, T., Lancaster, K.E., Ha, T.V., Go, V.F., 2018. "[Drinking is] like a rule that you can't break": perceived barriers and facilitators to reduce alcohol use and improve antiretroviral treatment adherence among people living with HIV and alcohol use disorder in Vietnam. Subst. Use Misuse 53 (7), 1084-1092.

Hershow, R.B., Ha, T.V., Sripaipan, T., Latkin, C., Hutton, H.E., Chander, G., Bui, Q., Nguyen, V.Q., Frangakis, C., Go, V.F., 2020. Perpetration of intimate partner violence among men living with HIV in northern Vietnam. AIDS Behav. https://doi.org/10. 1007/s10461-020-02813-5 and the PMID: 32078077.

Horton, P., Rydstrom, H., 2011. Heterosexual masculinity in contemporary Vietnam: privileges, pleasures, and protests. Men Masc. 14 (5), 542-564.

Hutton, H.E.L., K. E, Zuskov, D., Mai, N.V.T., Quynh, B.X., Chander, G., Latkin, C.A., Vu, P.T., Sripaipan, T., Ha, T.V., Go, V.F., 2018. Cultural Adaptation of Two Evidencebased Alcohol Interventions for Antiretroviral Treatment Clinic Paitents in Vietnam. Manuscript submitted for publication.

Jansen, H.A., Nguyen, T.V., Hoang, T.A., 2016. Exploring risk factors associated with intimate partner violence in Vietnam: results from a cross-sectional national survey. Int. J. Public Health 61 (8), 923-934.

Kachadourian, L.K., Quigley, B.M., Leonard, K.E., 2014. Alcohol expectancies and evaluations of aggression in alcohol-related intimate-partner verbal and physical aggression. J. Stud. Alcohol Drugs 75 (5), 744-752.

Kulis, S.S., Marsiglia, F.F., Nuno-Gutierrez, B.L., Corona-Lozano, M.D., MendozaMelendez, M.A., Kiehne, E., Jager, J., Ayers, S.L., Han, S., 2019. Reciprocal effects of alcohol use and violence perpetration among early adolescents in Mexico: a gendered analysis. J. Youth Adolesc. 48 (8), 1519-1531.

Leonard, K.E., Senchak, M., 1993. Alcohol and premarital aggression among newlywed couples. J. Stud. Alcohol Suppl. 11, 96-108.

Li, Y., Marshall, C.M., Rees, H.C., Nunez, A., Ezeanolue, E., Ehiri, J., 2014. Intimate partner violence and HIV infection among women: a systematic review and metaanalysis. J. Int. AIDS Soc. 17, 18845.

Lincoln, M., 2016. Alcohol and drinking cultures in Vietnam: a review. Drug Alcohol Depend. 159, 1-8.

Luu, B.N., Nguyen, T.T., Newman, I.M., 2014. Traditional alcohol production and use in three provinces in Vietnam: an ethnographic exploration of health benefits and risks. BMC Public Health 14, 731.

Machisa, M.T., Christofides, N., Jewkes, R., 2016. Structural pathways between child abuse, poor mental health outcomes and male-perpetrated intimate partner violence (IPV). PLoS One 11 (3), e0150986.

McIntosh, R.C., Hurwitz, B.E., Antoni, M., Gonzalez, A., Seay, J., Schneiderman, N., 2015 The ABCs of trait anger, psychological distress, and disease severity in HIV. Ann. Behav. Med. 49 (3), 420-433.

McMahon, J.M., Braksmajer, A., Zhang, C., Leblanc, N., Chen, M., Aidala, A., Simmons, J., 2019. Syndemic factors associated with adherence to antiretroviral therapy among HIV-positive adult heterosexual men. AIDS Res. Ther. 16 (1), 32.

Mitchell, J., Wight, M., Heerden, A.V., Rochat, T.J., 2016. Intimate partner violence, HIV, and mental health: a triple epidemic of global proportions. Int. Rev. Psychiatry 28 (5), 452-463.

Murray, L.K., Kane, J.C., Glass, N., Skavenski van Wyk, S., Melendez, F., Paul, R., Kmett Danielson, C., Murray, S.M., Mayeya, J., Simenda, F., Bolton, P., 2020. Effectiveness of the Common Elements Treatment Approach (CETA) in reducing intimate partner violence and hazardous alcohol use in Zambia (VATU): a randomized controlled trial. PLoS Med. 17 (4), e1003056.

Murshid, N.S., Murshid, N., 2018. Intergenerational transmission of marital violence: results from a nationally representative sample of men. J. Interpers. Violence 33 (2), 211-227.

Nguyen, T.D., 2006. Prevalence of male intimate partner abuse in Vietnam. Violence Against Women 12 (8), 732-739.

O'Farrell, T.J., Fals-Stewart, W., Murphy, M., Murphy, C.M., 2003. Partner violence before and after individually based alcoholism treatment for male alcoholic patients. J. 
Consult. Clin. Psychol. 71 (1), 92-102.

Okafor, C.N., Christodoulou, J, Bantjes, J., Qondela, T, Stewart, J., Shoptaw, S, Tomlinson, M., Rotherman-Borus, M.J., 2018. Understanding HIV risk behaviors among young men in South Africa: a syndemic approach. AIDS Behav. 22 (12), 3962-3970.

Osgood, W.D., Johnston, L.D., O'Malley, P.M., Bachman, J.G., 1988. The generality of deviance in late adolescence and early adulthood. Am. Soc. Rev. 53 (1), 81-93.

Pan, H.S., Neidig, P.H., O'Leary, K.D., 1994. Predicting mild and severe husband-to-wife physical aggression. J. Consult. Clin. Psychol. 62 (5), 975-981.

Perinelli, E., Gremigni, P., 2016. Use of social desirability scales in clinical psychology: a systematic review. J. Clin. Psychol. 72 (6), 534-551.

Quigley, B.M., Leonard, K.E., 2006. Alcohol expectancies and intoxicated aggression. Aggress. Violent Behav. 11 (5), 484-496.

Reed, E., Silverman, J.G., Welles, S.L., Santana, M.C., Missmer, S.A., Raj, A., 2009. Associations between perceptions and involvement in neighborhood violence and intimate partner violence perpetration among urban, African American men. J. Community Health 34 (4), 328-335.

Reyes, H.L., Foshee, V.A., Bauer, D.J., Ennett, S.T., 2012. Developmental associations between adolescent alcohol use and dating aggression. J. Res. Adolesc. 22 (3), $526-541$.

Rydstrom, H., 2003. Encountering "Hot" anger: domestic violence in contemporary Vietnam. Violence Against Women 9 (6), 676-697.

Sheehan, B.E., Lau-Barraco, C., 2019. A daily diary investigation of self-reported alcoholrelated direct and indirect aggression. Aggress. Behav. 45 (4), 463-471.

Shorey, R.C., Stuart, G.L., McNulty, J.K., Moore, T.M., 2014. Acute alcohol use temporally increases the odds of male perpetrated dating violence: a 90-day diary analysis. Addict. Behav. 39 (1), 365-368.

Sobell, L.C., Brown, J., Leo, G.I., Sobell, M.B., 1996. The reliability of the Alcohol Timeline Followback when administered by telephone and by computer. Drug Alcohol Depend. 42 (1), 49-54.

Stith, S.M., Smith, D.B., Penn, C.E., Ward, D.B., Tritt, D., 2004. Intimate partner physical abuse perpetration and victimization risk factors: a meta-analytic review. Aggress. Violent Behav. 10 (1), 65-98.

Straus, M.A., Douglas, E.M., 2004. A short form of the Revised Conflict Tactics Scales, and typologies for severity and mutuality. Violence Vict. 19 (5), 507-520.

Stuart, G.L., Ramsey, S.E., Moore, T.M., Kahler, C.W., Farrell, L.E., Recupero, P.R., Brown, R.A., 2003. Reductions in marital violence following treatment for alcohol dependence. J. Interpers. Violence 18 (10), 1113-1131.

Stuart, G.L., Shorey, R.C., Moore, T.M., Ramsey, S.E., Kahler, C.W., O’Farrell, T.J., Strong, D.R., Temple, J.R., Monti, P.M., 2013. Randomized clinical trial examining the incremental efficacy of a 90-minute motivational alcohol intervention as an adjunct to standard batterer intervention for men. Addiction 108 (8), 1376-1384.

Sugarman, D.B., Hotaling, G.T., 1997. Intimate violence and social desirability: a metaanalytic review. J. Interpers. Violence 12 (2), 275-290.

Temple, J.R., Shorey, R.C., Fite, P., Stuart, G.L., Le, V.D., 2013. Substance use as a longitudinal predictor of the perpetration of teen dating violence. J. Youth Adolesc. 42 (4), 596-606.

Tran, B.X., Nguyen, N., Ohinmaa, A., Duong, A.T., Nguyen, L.T., Van Hoang, M., et al., 2013. Prevalence and correlates of alcohol use disorders during antiretroviral treatment in injection-driven HIV epidemics in Vietnam. Drug Alcohol Depend. 127 (1-3), 39-44.

Tran, B.X., Nguyen, L.T., Do, C.D., Nguyen, Q.L., Maher, R.M., 2014. Associations between alcohol use disorders and adherence to antiretroviral treatment and quality of life amongst people living with HIV/AIDS. BMC Public Health 14, 27.

Tschann, J.M., Flores, E., Pasch, L.A., Marin, B.V., 2005. Emotional distress, alcohol use, and peer violence among Mexican-American and European-American adolescents. J. Adolesc. Health 37 (1), 11-18.

Vakili, S., Sobell, L.C., Sobell, M.B., Simco, E.R., Agrawal, S., 2008. Using the Timeline Followback to determine time windows representative of annual alcohol consumption with problem drinkers. Addict. Behav. 33 (9), 1123-1130.

White, H.R., Chen, P.H., 2002. Problem drinking and intimate partner violence. J. Stud. Alcohol 63 (2), 205-214.

Wilson, I.M., Graham, K., Taft, A., 2017. Living the cycle of drinking and violence: a qualitative study of women's experience of alcohol-related intimate partner violence. Drug Alcohol Rev. 36 (1), 115-124.

World Health Organization, 2010. Preventing Intimate Partner and Sexual Violence against Women: Taking Action and Generating Evidence. World Health Organization, Geneva, Switzerland.

World Health Organization, 2013. Global and Regional Estimates of Violence against Women: Prevalence and Health Effects of Intimate Partner Violence and Non-Partner Sexual Violence. World Health Organization, Geneva, Switzerland.

Yount, K.M., Higgins, E.M., Vanderende, K.E., Krause, K.H., Minh, T.H., Schuler, S.R., Anh, H.T., 2015. Men's perpetration of intimate partner violence in Vietnam: gendered social learning and the challenges of masculinity. Men Masc. 19 (1), 64-84.

Yu, R., Nevado-Holgado, A.J., Molero, Y., D’Onofrio, B.M., Larsson, H., Howard, L.M., Fazel, S., 2019. Mental disorders and intimate partner violence perpetrated by men towards women: a Swedish population-based longitudinal study. PLoS Med. 16 (12), e1002995.

Zhao, M., Liu, B., Zheng, T., Xu, J., Hao, Y., Wang, J., Zhang, X., Nie, W., Wang, C., Wang, F., Jiao, M., Wu, Q., Liang, L., 2019. Factors associated with hostility among people living with HIV/AIDS in Northeast China: a cross-sectional study. BMC Public Health 19 (1), 1189. 